\title{
COVID-19: Bat-borne viral outbreaks and its prevention through ecological intervention with reference to India
}

\section{Malik Khired Tanveer网}

Received: 25.03.2020
Revised: 05.05.2020

\begin{abstract}
The present paper discusses different methods to stop COVID-19 pandemic which bring the whole of world to a standstill. The (COVID-19) Coronavirus Disease- 19 caused by (SARS-CoV-2) Severe Acute Respiratory Syndrome Coronavirus 2 is highly transmittable and pathogenic viral infection which recently emerged in Wuhan province of China and has rapidly spread throughout the World. The information regarding its intermediate source of origin and transfer to humans is still unknown or very less known, but its fast transmission from human to human has been confirmed widely. Till date no clinically approved antiviral drug or vaccine has been developed against COVID-19. In the present paper, authors tries to summarize and comparatively analyse the deadly virus author also discuss that how this virus poses a constant threat to sub continental nations especially India. The present paper also suggests number of ecological interventions to protect humans.
\end{abstract}

Key words: COVID-19, Coronavirus disease 19, Ecological interventions, Antiviral drug, Bats.

\section{Introduction}

The planet Earth has come to a stand-still and everyone in any part of the world is under partial or complete lockdown. Such conditions have neverbeen seen in the history of human civilisation. The deadly Corona virus $(\mathrm{CoV})$ disease is to blame for. The deadly Coronavirus Disease 2019 (COVID-19) outbreak caused by Severe Acute Respiratory Syndrome Coronavirus 2 (SARS-CoV-2) was reported for the very first time in December 2019, in Wuhan province of China (Khan et al., 2020). From there the COVID-19 has rapidly spread from its epicentre to global scale and now is decisively recognised as a pandemic by the World Health Organization (World Health Organization, 2020). It has become a major threat to world health, fauna, economy and environment. The fast transmission rate and lack of vaccines for this deadly SARS$\mathrm{CoV}-2$, led to a major global health emergency. The Prevailing situations of pandemic and lockdown which scared the public, and initiated a psychological stress among the people in almost every part of the world. (Cohen and Kupferschmidt, 2020). Similar to SARS-CoV-2, other viruses

\section{Author's Address}

Department of Environmental Sciences, Bhagwant University, Ajmer (Rajasthan)

E-mail.: khired@gmail.com such as Severe Acute Respiratory Syndrome Coronavirus (SARS-CoV), the dangerous Middle East Respiratory Syndrome Coronavirus (MERS$\mathrm{CoV})$, The Marburg virus, and the dangerous Ebola virus, have also caused major outbreaks in recent history. A number of deaths have been caused by such outbreaks and its eradication, vaccination and control will cost billions of dollars, worldwide (Allocati et al., 2016; Fan et al., 2019).

Primary source of Virus: Bats are blamed for this deadly disease transmission. Such viruses are reported to have been naturally found in bats, especially coronaviruses which make up approximately $31 \%$ of the viruses in bats as reported by (Allocati et al., 2016; Afelt et al., 2018). Humans are infected by these viruses either by direct consumption or contact or through the intermediate hosts (Chan et al., 2013; Allocati et al., 2016). The higher species diversity in bats (over 1400), their strong and higher resistance to viral infections, longer lifespan spanning over 30 years on average and migratory factor makes them a major reservoir for pathogens and therefore, their chances to transmit pathogens to other species are very high in large areas (Allocati et al., 2016; Frick et al., 2019; Banerjee et al., 2020). Nearly 5717 bat-associated animal viruses were detected upto 
the year 2016, in a total of 207 bat species, in 77 different countries (Allocati et al., 2016). The nocturnal and solitary living characteristics of bats make them very difficult to study (Frick et al., 2019). It is highly likely that a number of dangerous and deadly viruses may be present in different bat species which have not been found and studied so far. There is an urgent need for regular and efficient monitoring, studying and surveillance in localities where in human beings and bats share a common habitat.

Destruction of their habitat: There is no denying in the fact that bats are very essential for our ecosystem as they maintain the ecological balance in the environment but the rapid clearing of forests for agriculture, urbanization and for making space for the ever expanding human population have greatly damaged and transformed the natural ecological niche of bats to a great extent (Walsh et al., 2017). There has been an ever increasing growth of our communities, localities, states and country population, year by year our numbers are increasing which ultimately leads to deforestation and land use for infrastructure, housing roads and agriculture. The countries lying in Southeast Asia (SEA) region are undergoing a population explosion and have lost nearly $30 \%$ of forest cover only in the previous 40 years. The growth in human population in SEA region is expected to grow to around 250 million by the upcoming year 2030 in comparison to only 130 million from the years 2001 and 2011 in a research by (Afelt et al., 2018).

Bat population in India: One of the most ecologically diverse countries in the world, India is renowned for its majestic wildlife, and studies of its natural history abound, but the bats of India have hardly ever been studied and mentioned, and very little is known about them (Shahroukh, 1995). Bats are an important part of our biodiversity but have not been studied extensively. With at least 109 species India has an incredibly vast diversity of bat species (Shahroukh, 1995). This includes one of the largest bat species in size in the world, the Indian flying fox (Pteropus giganteus); one of the most colourful bats in the world, the orange and black colour painted bat (Kerivoula picta); and one of the rarest species, Salim Alis fruit bat(Latidens salimalii). The habits and habitats of India's bats are very diverse. Right from the higher altitudes of the Himalayan mountains up-to to the dry deserts of the Northwest, to the moist tropical forests of the East and South, there are bats that feed on fruit, nectar, insects, frogs, and even other bats also. In India the majority of bats population are in North Eastern states of the country. The species richness is also confined to the north eastern region.

Shifting of Bat colonies near human inhabitation: Over the years, there has been a significant shift of bats population closer to the human inhabitation. As a result of an ever increasing population, urbanization and deforestation, declining biodiversity, the colonies of bats trying to adapt and nest in the human inhabited village and city settlements and environments, in the vicinity of human inhabitation areas (Jung and Threlfall, 2018; Li et al., 2019). Typically diverse environmental conditions are generated close to the human populations due to the above mentioned reasons, these changed environmental conditions makes it suitable for a diverse range of bat species to live and thrive there, not seen there before (Walsh et al., 2017; Jung and Threlfall, 2018), easy access to food could be the reason. Because of this, the number of bat species and the viruses present in bats will automatically rise. The luminous lightings of the houses attract bats in search of insects and pests. Fruit eating bats are attracted towards gardens and fields. The dark areas in the house and barns attract the bats which live in caves.

When a number of bat species interact amongst themselves, their viruses also interact and are passed from one another, theses deadly viruses will then be transferred to the human beings through different means such as: direct hands contact, contamination of potable ground water by bat faeces or urine, and infection to domesticated animals (Jung and Threlfall, 2018). Also the characteristics that are very unique and specific in bats such as gathering or assemblage during the roosting process, their feeding practices and a very resilient immune systems help in the continued accumulation and mixing of different viruses in their body that may lead to formation of RNA viruses that are highly dangerous, recombinant, novel mutant, and reassortant (Chan et al., 2013). 


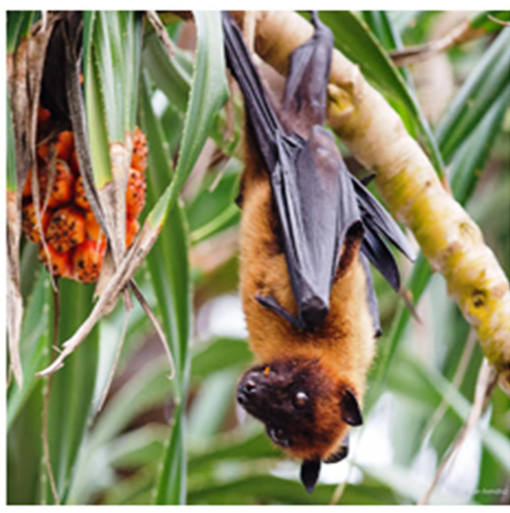

Plate 1: Indian Flying Fox
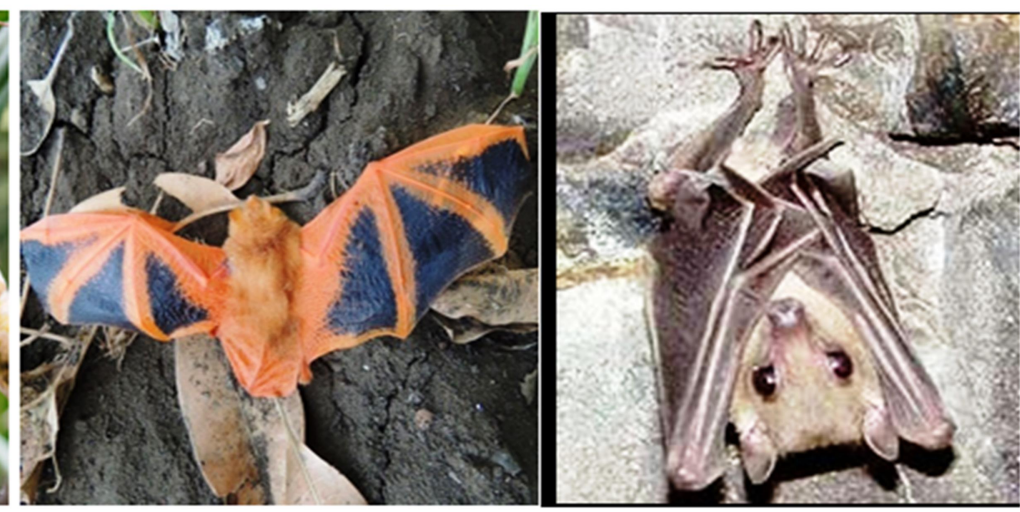

Plate 2: Painted Bat
Plate 3: Salim Alis Fruit Bat

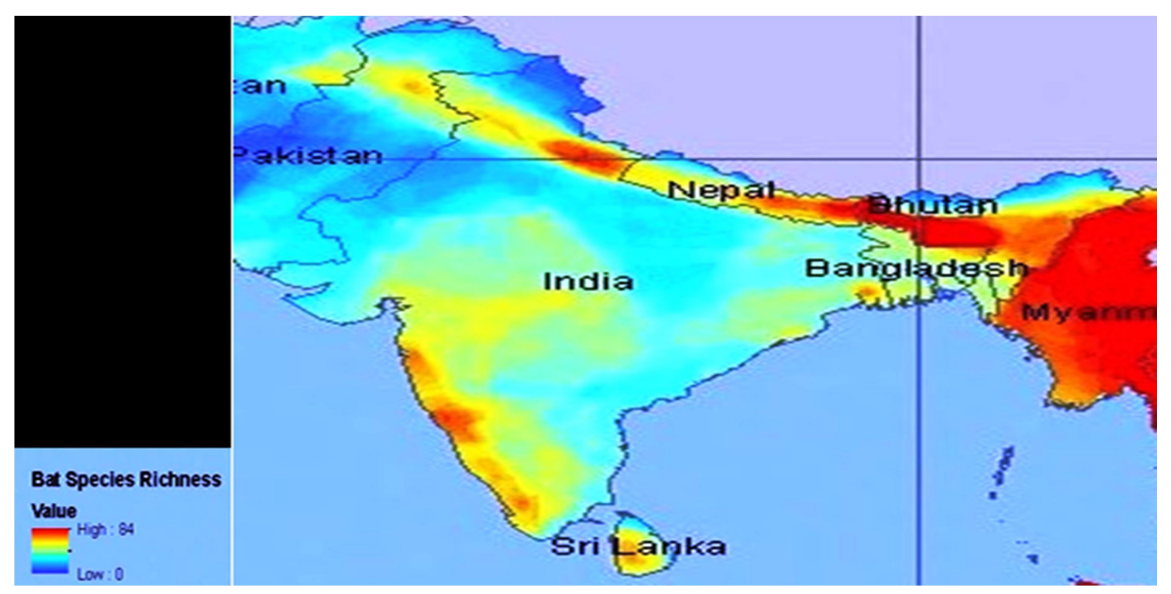

Fig 1: Bat species richness in India, Source: (IUCN, Batsworld.com)

Bats in Delhi: Looking for bats one does not have to go to deep forests or caves but they are right in the National capital of the country. There is a considerable population of fruit eating bats in New Delhi. These fruit bats (Pteropus giganteus), commonly known as the Indian flying fox, may be seen on almost all the Arjuna (Terminalia arjuna) trees on and around Janpath in New Delhi (Rajlakshmi Mishra). Bats can also be seen on and around the Ashoka trees (Polyalthia longifolia) and Jamun (Syzygium cumini) trees in Motilal Nehru Marg areas and Akbar Road, sharing their abode with some of the biggest political names of the nation, including the Prime minister. Given the extremely fast transmission of this viral disease and its lack of vaccination, the only way to combat it is by using ecological intervention. Some of these ecological interventions are discussed below.
1. Habitat preservation: There is an urgent need to preserve and isolate the natural habitat of bats. Olivero et al., (2017) determined that deforestation on large scale has been related to viral outbreaks throughout the world. Ill practices of deforestation should be stopped immediately, everywhere and compensatory afforestation should be done to give the habitat back to wild life. After the outbreak of such viral diseases millions and crores are spent only to counter the disease, to diagnose, vaccinate the patients and for eradication of the disease. But very less care and focus is given to the basic preventive measures such as afforestation and sustaining the wildlife habitats. Neither our government. nor the citizens are concerned in this regard. The world community have the need to recognise the importance of respecting the wildlife and its habitats for their wellness. 


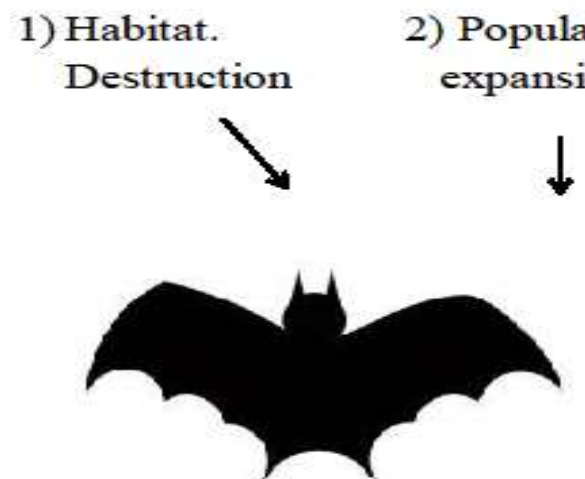

Primary host- Bat

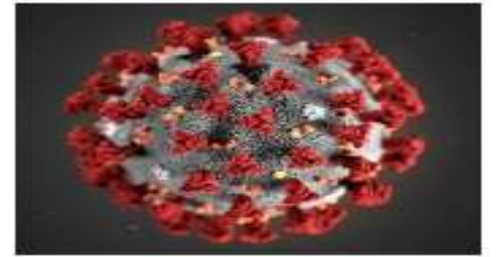

SARS-COV-2
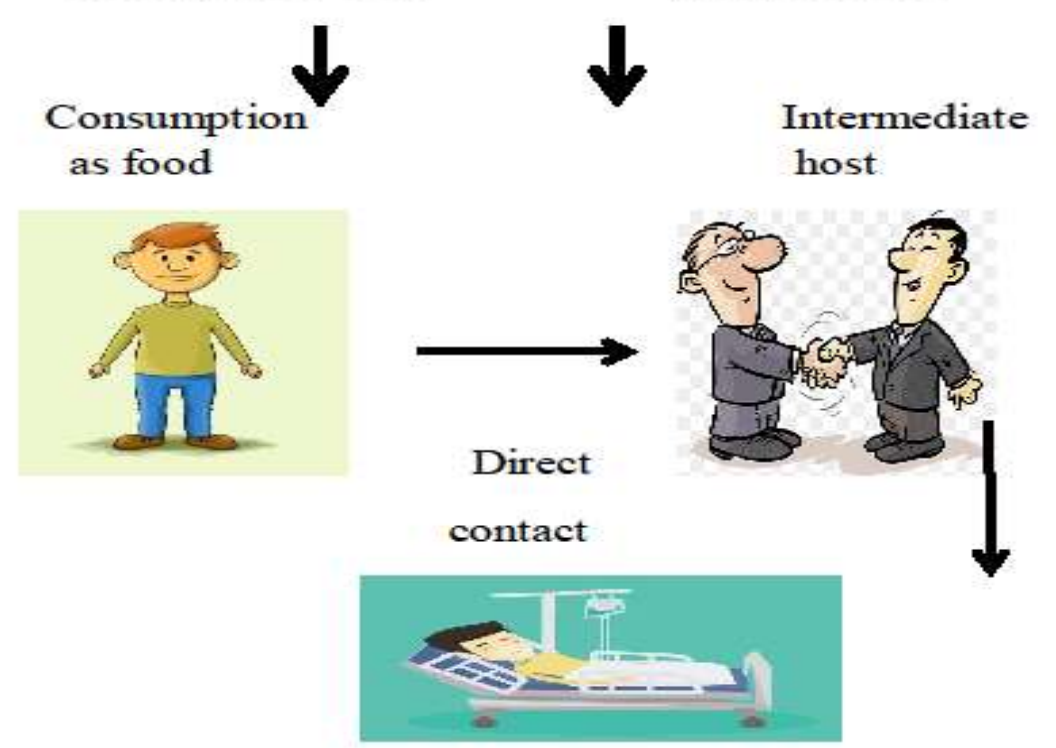

COVID-19 Pneumonia

Fig 2: Diagrammatic representation of transmission of COVID-19.

2. Bat hunting and consumption: Though Bat hunting and consumption is not so common in India but the rapid transmission of such viral diseases in our neighbouring countries is a major cause of has concern, Nearly 56 species of bats are hunted for consumption purpose in Asia (Mildenstein et al., A 2016). In addition to that, live killing, and eating of under cooked meat of bats can be the utmost reason wit for such viral infections in humans (Chan et al., 20 2013; Fan et al., 2019).
3. Controlling human population growth: India is the second most populated nation in the world after China, China being the most populous country has seen three major bat origin COVs epidemics till now (Fan et al., 2019; Khan et al., 2020). According to the research many bat related viral infections have been seen and reported in lands with higher population density (Plowright et al., 2015). So, in this regard human population growth needs to be stabilised and regulated through family 
planning and legislations especially of Asian countries.

4. Universal ban of wildlife trade: In spite of all the efforts of world environment and animal bodies to curb the menace of wildlife trade, it has not decreased but has been increasing each year. New viruses having pandemic potentials emerge largely due to the un organised and illegal trade of wildlife as seen in the case of COVID-19 and similarly other outbreaks (Boseley, 2020). Hence, keeping in mind the fatal health problems, biosafety of the nation, universal public health, and economic inflows and outflows, it is high time to eradicate the menace of wild life trade.

5. Research, wildlife monitoring and survey: Efficient and effective scientific research is the guiding light to any environmental problem. Universally it is very important to research and monitor the presence or absence of wild life carrying viruses. Scientific surveys of bat

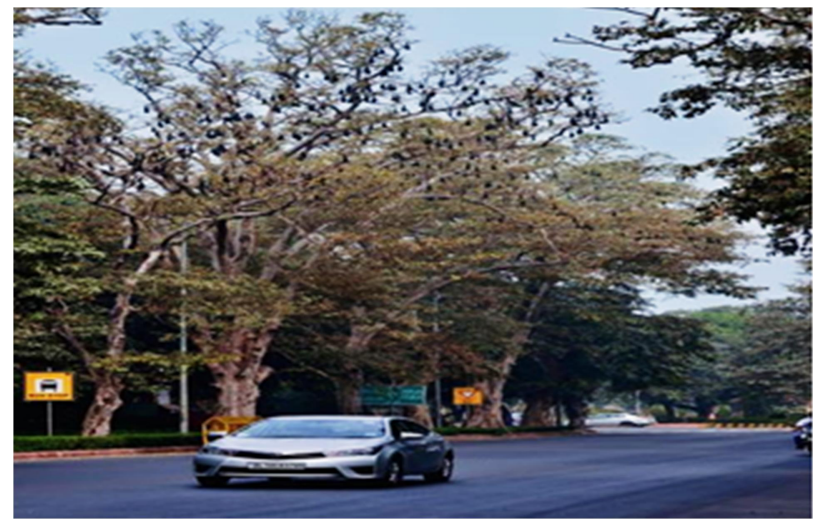

Fig 3. Bats hanging from trees in Janpath area (New Delhi).

\section{Conclusion}

Many of the severe illnesses which have been reported because of the un-natural association that lies between the bats and human-beings, give us an indication that there is an urgent need to adopt some preventive ecological intervention for the control of ecosystem in a swiftly dynamic world. There is a need to demarcate, preserve and conserve bats in their natural habitat because they are an important part of our ecosystem. We need to understand the concept of co-existing with bats and the only way to do so is by respecting their territories. Continuous deforestation and invasion of their territories has to stop now. Bat hunting and population, inhabitation and migration may give instant knowledge with regards to the origin, travel and spill overs that may have happened with regards to the virus containing materials associated with the wildlife in any particular area, country or continent.

6. Scientific ecological research: The Government of India has started a nationwide research and development (R\&D) initiative to combat corona virus spread and transmission. The Department of Science and Technology - Science and Engineering Board (DST-SERB) has announced several special scientific research projects as early as April 01 2020 within weeks of it's out-break in India. The first set of 5 projects have been selected for further development into implementable technologies level. These projects were selected only after the peer-review and assessment approval by a Special Expert Committee of CoVID-19 projects and programmes.

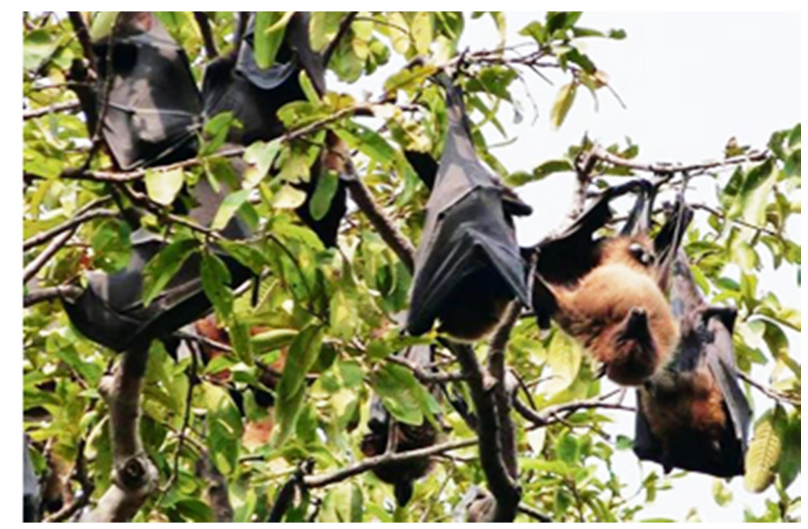

consumption is another cause of concern and should be banned at the earliest. There is also an urgent need to increase the focus and funding on research, wildlife monitoring and survey of bats because till now, we know very less about these ecologically important animals. The pandemic of COVID-19 has gripped the world and brought everything to a stand-still, such an extra-ordinary situation definitely requires extra-ordinary measures to stop likewise pandemics in future. The steps given in this review paper shall prove to be decisive in restricting bats to their natural habitat and hence the viruses associated with them. 


\section{Malik Khired Tanveer}

\section{References}

Afelt, A., Frutos, R. and Christian, D. 2018. Bats, coronavirus, and deforestation: toward the emergence of novel infectious diseases spread. Frontiers in Microbiology. 9: 702.

Allocati, N., Petrucci, A.G. and Giovanni, P.Di. 2016. Bat-man disease spread and transmission: zoonotic pathogens from wildlife reservoirs and its transmission into the human populations. Cell Death Disease. 2: 16048.

Banerjee, A., Baker, M.L. and Kulcsar, K. 2020. Novel insights into the immune systems of bats. Frontiers in Immunology. 11: 26.

Boseley, S. 2020. Calls for Global Ban on Wild Animals Market amidst Coronavirus Outbreak scare. The Guardian.

https://www.theguardian.com/science/2020/jan/24/calls-forglobal-ban-wild-animal-markets-amid-coronavirusoutbreak

Chan, J.F., To,K.K. and Tse, H. 2013. Interspecies transmission and spread of viral diseases and emergence of novel viruses: important lessons from bats and birds. Trends in Microbiology. 21: 544-555.

Cohen, J. and K. Kupferschmidt, K. 2020. Strategies shift as coronavirus pandemic looms on us. Science, 367: 962-963. https://science.sciencemag.org/

Fan, Y., Zhao, K. and Shi, Z.L. 2019. Bat coronaviruses in China. Viruses. 11: 210.

Frick, W.F., Kingston, T. and Flanders, J. 2019. A review of the major threats and challenges to global bat conservation program. Annals of the New York Academy of Sciences.

Jung, K. and Threlfall, C.G. 2018. Trait-dependent tolerance of bats to urbanization: a global meta-analysis study. Proceedings. Biological sciences. 285: 20181222.
Khan, S., Nabi, G. and Han, G. 2020. Novel coronavirus: how things are in Wuhan province. Clinical Microbiology and Infectious Diseases. 26(4): 399-400.

Li, H., Mendelsohn, E. and Zong, C. 2019. Human-animal interactions and conflicts and fatal bat coronavirus spillover and transmission potential among the rural population in Southern China. Biosafety and Health. 1: 84-90.

Mildenstein, T., Tanshi, I. and P.A. Racey, P.A. (Eds.) 2016. Bats in the Anthropocene: conservation of bats in this changing world. Exploitation of Bats for Bushmeat, vaccines and Medicine. Springer International, New York, NY.

Olivero, J., Fa, J.E. and Real, R. 2017. Recent loss of closed forests is directly associated with Ebola virus disease outbreaks. Scientific Reports. 7: 14291.

Plowright, R.K., Eby, P. and Hudson, P.J. 2015. Ecological dynamics of the emerging bat virus spillover. Proceedings. Biological sciences. 282: 20142124.

Shahroukh, M. 1995. The bats of India. Volume 13, Issue 2.

Walsh, M.G., Wiethoelter, A. and Haseeb, M.A. 2017. The impact of human population and its pressure on the flying fox habitat and niches and the potential consequences for Hendra virus spill over report. Scientific Reports. 7: 8226.

World Health Organization, 2020 World Health Organization report. WHO characterizes COVID-19 as a major pandemic.

https:/www.who.int/emergencies/diseases/novel-coronavirus2019/events-as-they-happen 